\title{
Innovation Management and Performance Framework for Research University in Malaysia
}

\author{
Tan Owee Kowang ${ }^{1}$, Choi Sang Long ${ }^{1} \&$ Amran Rasli ${ }^{2}$ \\ ${ }^{1}$ Faculty of Management, Universiti Teknologi Malaysia, Johor Bahru, Malaysia \\ ${ }^{2}$ Innovation and Commercialisation Centre, Universiti Teknologi Malaysia, Johor Bahru, Malaysia \\ Correspondence: Tan Owee Kowang, Faculty of Management, Universiti Teknologi Malaysia, 81310 Johor \\ Bahru, Malaysia. Tel: 60-12-789-1560. E-mail: oktan@utm.my
}

Received: January 22, 2015 Accepted: February 22, 2015 Online Published: May 27, 2015

doi:10.5539/ies.v8n6p32

URL: http://dx.doi.org/10.5539/ies.v8n6p32

\begin{abstract}
Institutions of Higher Learning (IHL) in Malaysia are recognized as the core of new innovation development. This paper empirically studies one of IHLs in Malaysia with the objectives to gauge the perceived important level of success factors for innovation management, and to examine the relationship between innovation management success factors versus innovation performance. Descriptive statistical analysis and Pearson correlation test are used to validate the preliminary research framework. Finding from the study presents an interesting managerial implication where success factor that perceived as the most important is not strongly correlated with innovation performance. Suggestions to enhance the innovation performance are proposed, which comprising securement of greater research funding, expanding number and scope of collaboration or cooperation with external parties as well as continuously upgrading and enhancing the level of expertise. Finally, a revised framework of innovation performance management for Research University is proposed bases on literature review and complemented by the result of this study.
\end{abstract}

Keywords: innovation management, innovation performance, innovation success factors, innovation framework, institutions of higher learning

\section{Introduction}

Business competition on the level of innovation has made innovation management as one of the core component towards business success. Innovation management is important because it enhances an organization's competitive advantage by introducing new products, services, technologies and breakthrough ideas (Michael, 2008). An upbeat innovation management practice is considered as the main driver for the development of new idea, product, service and technology. Hence, Research and Development (R\&D) based organizations in both private and public sectors had started reviewing their innovation management practices in order to promote a positive innovation environment within the organization (Antonio \& Jose, 2008), with the ultimate aim to enhance innovation performance.

\section{Research Background}

In Malaysia, Institutions of Higher Learning are recognized as the core of new innovation development. As such, few universities in Malaysia had been upgraded to the status of Research University (RU) to accentuate research, development and commercialization (R\&D\&C) activities within the university. Hence, innovation performance and innovation management are crucial for RUs in order for the universities to support the country's vision to transform to as an innovation-rich nation by year 2020 .

Hence, the primary objectives for the study are to gauge the perceived important level of success factors for innovation management within a research group in one of RUs in Malaysia, namely KRA (Knowlwdge-based Research Alliance) research group. In addition, the study also examines the relationship between innovation management success factors versus innovation performance. As such, two objectives (RO) are developed for this study:

1) RO 1: To gauge the perceived important level of success factors for innovation management in KRA research group. 
2) RO 2: To investigate the relationship between innovation management success factors and innovation performance in KRA research group.

\section{Literature Review}

\subsection{Innovation in Research University}

Innovation refers to the successful exploitation of new creativity (Gurteen, 1998; Leonard \& Swap, 1999; O'Sullivan \& Dooley, 2009). Therefore, creativity is recognized as the key element for the development of "innovation" (Chiesa, 2001; O'Sullivan \& Dooley, 2009). While innovation is the outcomes of those new creativity after undergone a research and development process that involve several progressions such as planning, implementation and control. Innovation also refers as the outcomes of research that had been commercialized or available to society and market, and it is not necessary needs to be novel or ground-breaking (Rasli, 2006). Hence, within the context of this paper, innovation is defined as research activities that transforming human's creativity expression into idea, process, services, products or technology and make it available to society and markets.

\subsection{Success Factors for Innovation Management}

Series of innovation management success factors had been identified by prior researchers (Pane et al., 2003; Johnston \& Bate, 2007; Cooper \& Kleinschmidt, 2007) which could be grouped and categorized into five main factors; (1) innovation strategy; (2) innovation leadership; (3) organization structure; (4) organization culture and (5) innovation resources.

\subsubsection{Innovation Strategy}

Innovation strategy contained a detail action plan to accomplish innovation goals (Johnston \& Bate, 2007), and it is an important factor for innovation success (Pane et al., 2003). A well-planned innovation strategy shall be integrated with business strategy to ensure both strategies share a common set of vision and mission (Wong, 2005). In addition, study conducted by Cooper and Kleinschmidt (2007) revealed that a successful innovation strategy need to be communicated effectively across the organization. On top of this, a successful innovation strategy required an enduring commitment from top management in the manners of encouragement, involvement, drive, support and funding (Sathe, 1898; Saleh \& Wang, 1993). Study done by Horvath (2011) revealed that top management commitment toward innovation strategy is positively correlated with the organization long term economy growth.

\subsubsection{Innovation Leadership}

Within the context of this study, leader is referring to the head of research group as well as leader of research projects. Leaders who are capable to develop innovative solution for the surrounding problems or challenges faced by the organization are the important asset for the organization (Byers et al., 2011).

In addition, leader must effectually pose an appropriate leadership style in order to maximize the opportunities that associated with innovation management (Yulk, 2010). Study conducted by prior researchers (Yulk, 2010; Byers et al., 2011) revealed that leadership style of supporting, empowerment and coaching offered more humanism, freedom and less procedures for organization members, as the result facilitated innovation process more effectively.

\subsubsection{Organization Structure}

Organization structure is the formal framework for the arrangement of organizations' functional departments and communication channels (Byers et al., 2011). Hence, the structure of an organization governs the outline of cross-functional communication flow and pattern of tasks allocation across the organization.

Cross functional integration and communication are important and has been recognized as tools that created a favorable environment for new ideas survival (Trott, 2005). Effective communication increases the number of new innovation through integration of cross functional ideas.

The nature of innovation which is ranged from incremental to revolutionary (Birinshaw \& Gibson, 2004) required a flexible and scalable organization structure to adapt the development on varies types of new innovative products or services (Larson \& Gobeli, 1988; Cooper, 2008; Cooper \& Kleinschmidt, 2007).

\subsubsection{Organization Culture}

Organizational culture refers to the combination set of numerous values, norms and rituals which shared by members of the organization and govern their behaviors of interaction among each other within the organization (Byers et al., 2011). A positive organizational culture promotes value of trust, collaboration, knowledge creation, 
sharing and openness to new ideas as well as tolerance to failure (Rahimi et al., 2011). In a positive organization culture environment, the level of acceptability and involvement toward innovation or changes by members in organization is superior (Hartmann, 2006; Valencia et al., 2010). In addition, positive organizational culture also promotes creativity, cooperation, collaboration and risk taking within the organization (Jassawalla \& Sashittal, 2002).

\subsubsection{Innovation Resources}

Innovation resources within the context of this study refer to financial resources, social capital and human resources. Lacking of innovation resources will hinder the innovation success (Delbecq \& Mills, 1985; Wong, 2005; Cooper \& Kleinschmidt, 2007). Financial resource of an organization outlined the natures of innovation activities, modes of technology acquiring and the number of innovation project contended by the organization (Metrick \& Yasuda, 2011).

Social capital refers to relationships among internal individuals who work within the organization as well as network between internal with external parties via collaboration and cooperation (Mol \& Birkinshaw, 2009; Zeng et al., 2010). Broad and effectual social capital widens the organization's access toward external capital resource, new technology information as well as updated market status (Kalnins \& Chung, 2006; Packalen, 2007).

Human resources management (HRM) forms the behavior and performance of individual within the organization (Gloet \& Berrell, 2003). An effective human resources strategy including recruitment process, training and retention schemes are crucial toward organization's innovation success (Cooper \& Kleinschmidt, 2007).

\subsection{Innovation Performance}

Organization Innovation Performance (OIP) is recognized broadly as effective tools to growth organizational performance and stay survived in global competitions. Therefore, various OIP indicators have been developed by prior researchers to measure organizational innovation performance level (Saleh \& Wang, 1993; Griffin \& Page, 1996; Panne et al., 2003; Wong, 2005; Hartmann, 2006; Lee \& Chang, 2006; Byers et al., 2011). Generally, measurement of OIP in research based organization that proposed by prior researchers could be divided into four categories (refer Table 1): (1) measurement on effectiveness of innovation; (2) measurement of success on technical performance; (3) measurement of financial success and (4) measurement of research network.

Table 1. Organization innovation performance (OIP) measures

\begin{tabular}{|c|c|c|}
\hline Category of OIP & $\begin{array}{l}\text { Proposed measures in } \\
\text { this research: }\end{array}$ & Sources: \\
\hline $\begin{array}{l}\text { Effectiveness of } \\
\text { innovation process }\end{array}$ & $\begin{array}{l}\text { a) Efficiency and } \\
\text { effectiveness } \\
\text { innovation process } \\
\text { b) Time to complete a } \\
\text { project }\end{array}$ & Saleh and Wang (1993), Griffin and Page (1996), Panne et \\
\hline $\begin{array}{l}\text { Technical } \\
\text { achievement }\end{array}$ & $\begin{array}{l}\text { c) Number of new } \\
\text { project, services or } \\
\text { product completed }\end{array}$ & $\begin{array}{l}\text { al. (2003), Wong (2005), Hartmann (2006), Lee and Chang } \\
\text { (2006), Raymond and St-Pierre (2010), Liao and Rice } \\
(2010) \text {, Byers et al. (2011). }\end{array}$ \\
\hline Financial success & $\begin{array}{l}\text { d) Research fund } \\
\text { granted }\end{array}$ & \\
\hline Research network & $\begin{array}{l}\text { e) Number of external } \\
\text { links }\end{array}$ & \\
\hline
\end{tabular}

\subsection{Conceptual Framework}

The conceptual framework for this study is developed from the comprehensive literature review. The framework is based on a concept where innovation management contextual factors have a direct effect on innovation performance. The conceptual framework for the innovation management contextual factors consists of 17 attributes that group into 5 innovation management success factors as independent variables, which are (a) Innovation Strategy, (b) Leadership, (c) Organization Structure, (d) Organization Culture and (e) Innovation 
Resources as shown in Figure 1.

Independent Variables

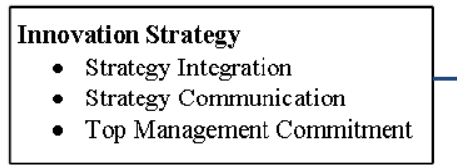

- Knowledge of I,eader

- Characteristic of Leader

- Leadership Style

- Motivation by T,eader

\begin{tabular}{|l|}
\hline Organization Structure \\
- Organization Flexibility \\
- Communication and Integration \\
- Task Allocation \\
- Cross Functional Team \\
\hline
\end{tabular}

Innovation Performance

- Efficiency and Effectiveness of Innovation Process.

- Number of New Project, Services or Product Completed/Developed.

- Research Fund Granted.

- Number of External Links

- Time to Complete a Project

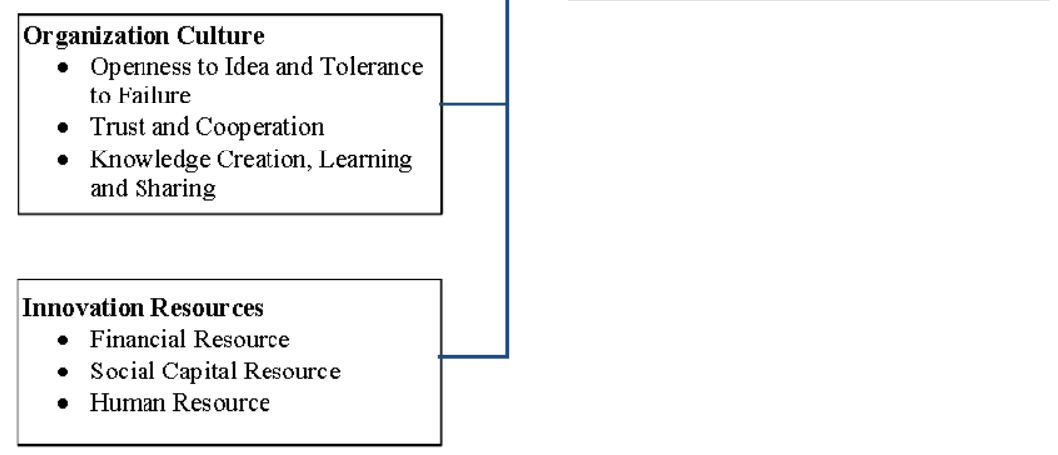

Figure 1. Conceptual framework

Meantime, dependent variables in the conceptual framework focuses on innovation performance in terms of (a) Efficiency and effectiveness of innovation process, (b) Number of new project, service or product completed, (c) Amount of research fund granted, (d) Number of external linkages, (e) Duration to complete a research project.

\section{Research Methodology}

\subsection{Population and Sampling}

The population for this study is 108 researchers from a RU in Malaysia. Sampling size for the study is defined base on sampling table proposed by Krejcie and Morgan (1970) which proposed that for the population of 108, the appropriate sampling size is 86 . Hence, a total of 86 respondents were randomly selected from the population of 108 researchers as the respondents for the study.

\subsection{Research Instrument}

A quantitative based instrument in the form survey questionnaire is used as research instrument for this study. Questionnaire is one of the most common instruments that applied in difference researches and is appropriate for quantitative approach (Zikmund, 1997; Kothari, 2008).

The questionnaire contains of 26 questions and is divided into three sections. Section A intends to collect information of respondents' demographic and academic background. Section B aims to gather respondents' feedback in regard with the perceived important level of innovation management success factors developed from literature review. In addition, section $\mathrm{C}$ is designed to measure respondents' perception on innovation performance base on the 5 performance measures discussed in literature review.

For the convenience of respondents, the questionnaire is formatted in a table form and the selection of answers 
involves circling the standard rating that is provided base on five points scale (refer Table 2).

Table 2. Range of scale

\begin{tabular}{ll}
\hline Scale & Level of Agreement/Importance \\
\hline 1 & Strongly Disagree/Not Important \\
2 & Disagree/Less Important \\
3 & Neutral/Moderate Important \\
4 & Agree/Important \\
5 & Strongly Agree/Very Important \\
\hline
\end{tabular}

\subsection{Analysis Tools}

Statistical Packages for Social Science (SPSS) of Windows Version is used as the main tool for the quantitative data analysis. The raw data is first keyed to the SPSS Data Editor and subsequently coded and "cleaned" for further analysis. Cronbach Alpha test is used as reliability test. A Cronbach Alpha reliability coefficient value of greater than 0.6 is suggested to be accepted (Rasli, 2006). Subsequently, descriptive analysis in term of "mean" or "average" is performed to generate the perceived important level of innovation management success factors and perceived level of innovation performance. This is followed by correlation analysis via Pearson Product Moment Correlation Coefficient test. Research instruments and statistical tools used in this study are summarized in Table 3.

Table 3. Research and analysis tools

\begin{tabular}{lll}
\hline $\begin{array}{l}\text { Research } \\
\text { Objective (RO) }\end{array}$ & Research Tools & Analysis Tools \\
\hline RO 1 & Questionnaire, & Reliability Test, Descriptive Statistics \\
& $\begin{array}{l}\text { Section B } \\
\text { RO 2 }\end{array}$ & Restionnaire, \\
& Section B and C & \begin{tabular}{l} 
Correlation Coefficient Test \\
\hline
\end{tabular}
\end{tabular}

\subsubsection{Descriptive Analysis}

The mean is a measure of central tendency; the measurement represents an overall picture of the data (Sekaran, 2003). Henn, Weinstein and Foard (2006) defined mean as the mathematical average; the sum of values for all cases divided by the total number of cases. In this research, mean is used to measure the central tendency of response from survey questionnaire in term of level of importance (for innovation management success factors) and level of innovation performance. The interpretation of the means score is based on proposal by Weiers (2008) as shown in Table 4.

Table 4. Interpretation of overall mean $(\mu)$

\begin{tabular}{ll}
\hline Overall Mean $(\mu)$ & Interpretation \\
\hline $1.0 \leq \mu<1.5$ & Not Important/Strongly Disagree \\
$1.5 \leq \mu<2.5$ & Less Important/Disagree \\
$2.5 \leq \mu<3.5$ & Moderate Important/Neutral \\
$3.5 \leq \mu<4.5$ & Important/Agree \\
$4.5 \leq \mu \leq 5.0$ & Very Important/Strongly Agree \\
\hline
\end{tabular}




\subsubsection{Person Correlation}

Pearson product moment correlation coefficient test is used to investigate the strength of relationship between independent variables (innovation management's success factors) and dependents variable (innovation performance). The value of Pearson correlation coefficient (r) is ranged from -1 to +1 . A positive value indicated a positive relationship and via versa (Weiers, 2008). Moreover, " $r$ " value of zero indicates there is no relationship between both independent and dependent variables. The strength of correlation could be interpreted via suggestion by Evans (1996) as shown in Table 5.

Table 5. Interpretation of Pearson Correlation Coefficient (r)

\begin{tabular}{ll}
\hline $\mathrm{R}$ & Strength \\
\hline $0-0.19$ & Very weak \\
$0.20-0.39$ & Weak \\
$0.40-0.59$ & Moderate \\
$0.60-0.79$ & Strong \\
$0.80-1.00$ & Very strong \\
\hline
\end{tabular}

\section{Result}

\subsection{Respond Rate}

The final questionnaires were distributed to 86 respondents through e-mail on December 2013; two reminders were sent to respondents subsequently, however, only 13 responded. The same questionnaires were subsequently distributed personally to the other 73 researchers on February 2014. As the result, additional 51 completed questionnaires were collected. In summary, a total of 108 questionnaires had been distributed with 64 responded but two of the return questionnaire were incomplete, this made up the overall respond rate of $57 \%$.

\subsection{Reliability Test}

Cronbach Alpha reliability coefficient is applied as reliability test. Based on Tables 6, Cronbach Alpha reliability values for the innovation management success factors are found to be above 0.7947 . This implies that the data is statistically significant to proceed for further analysis. A Cronbach Alpha reliability value of greater than 0.6 is suggested to be adequate for testing the reliability of factors.

Table 6. Reliability analysis

\begin{tabular}{ll}
\hline Innovation Management Success Factors & Cronbach's Alpha \\
\hline Innovation Strategy & 0.8653 \\
Leadership & 0.8844 \\
Organization Structure & 0.7947 \\
Organization Culture & 0.8246 \\
Organization Resources & 0.8114 \\
\hline
\end{tabular}

\subsection{Perceived Important Level of Success Factors for Innovation Management}

The respondents' perception on the importance level of innovation management success factors are retrieved from Section B of survey questionnaire. The analysis of importance level focused on the 17 innovation management attributes. The individual mean score across the 17 innovation management attributes were summed up according to the categories of innovation management success factors. Mean score of attributes per success factor is subsequently calculated to form the mean score for success factor as shown in Table 7 . The mean scores reflect the perceived importance level of innovation management success factor by members of KRA research group. 
Table 7. Importance Ranking of Innovation Management Success Factors

\begin{tabular}{lll}
\hline Importance Ranking & Innovation Management Success Factors & Mean Score \\
\hline 1 & Innovation Strategy & 4.56 \\
2 & Innovation Resources & 4.51 \\
3 & Organizational Culture & 4.11 \\
4 & Organizational Structure & 4.10 \\
5 & Leadership & 4.08 \\
\hline
\end{tabular}

From Table 7, the perceived level of importance for all the five innovation management success factors are above 4.0, where innovation strategy and innovation resources are regarded as the most important factors with the mean of 4.56 and 4.51 respectively. While leadership is perceived as the least important with mean of 4.08 . The remaining two success factors; organization culture, organization structure are rated at 4.10 and 4.11 . Overall, bases on interpretation guideline of Table 4, it can be concluded that the respondents regarded that all the innovation management success factors are important for innovation management success in KRA research groups.

\subsection{Correlation}

Pearson Product Moment Correlation Coefficient test is used to assess the relationship between the perceived innovation performances of KRA research groups and the perceived important level of the 5 innovation management success factors i.e. Innovation Strategy, Leadership, Organizational Structure, Organizational Culture and Innovation Resources. The Pearson correlation coefficient analysis results via SPSS are presented in Table 8.

Table 8. Result of Pearson Correlation Analysis

\begin{tabular}{lll}
\hline & & Performance \\
\hline \multirow{3}{*}{ Performance } & Pearson Correlation & 1 \\
& Sig. (2-tailed) & .001 \\
& $\mathrm{~N}$ & 62 \\
\hline \multirow{3}{*}{ Strategy1 } & Pearson Correlation & $.469^{* *}$ \\
& Sig. (2-tailed) & .001 \\
& $\mathrm{~N}$ & 62 \\
\hline \multirow{4}{*}{ Leadership1 } & Pearson Correlation & $.390^{* *}$ \\
& Sig. (2-tailed) & .006 \\
& $\mathrm{~N}$ & 62 \\
\hline \multirow{5}{*}{ Structure1 } & Pearson Correlation & $.562^{* *}$ \\
& Sig. (2-tailed) & .000 \\
& $\mathrm{~N}$ & 49 \\
\hline \multirow{5}{*}{ Culture1 } & Pearson Correlation & $.588^{* *}$ \\
& Sig. (2-tailed) & .000 \\
& $\mathrm{~N}$ & 62 \\
\hline \multirow{5}{*}{ Resources1 } & Pearson Correlation & $.642^{* *}$ \\
& Sig. (2-tailed) & .000 \\
& $\mathrm{~N}$ & 62 \\
\hline
\end{tabular}

Note. ${ }^{*}$ Correlation is significant at the 0.01 level (2-tailed). 
From Table 8, all innovation management success factors are positively correlated with innovation performance. Bases on interpretation guideline of Table 5, success factor "Innovation Resource" is positively and strongly correlated with innovation management performance with correlation coefficient of 0.642 . However, innovation management success factor "Leadership" is positively but weakly correlated with innovation performance with correlation coefficient of 0.39 . While the other three innovation management success factors, "Organization Culture", "Organization Structure" and "Innovation Strategy" are moderately correlated with innovation performance with correlation coefficient ranged from 0.469 to 0.588 .

\section{Discussion}

\subsection{Addressing RO1: Important Level of Success Factors for Innovation Management}

Findings from this research revealed that all the five innovation success factors are perceived as important for innovation management within the context of KRA research groups. Innovation strategy and innovation resources are regarded as very important, meantime innovation leadership, organization structure and organization cultures are rated as important.

Respondents viewed innovation strategy management which consists of strategy communication, strategy integration and top management commitment as the most important factor for innovation management. The finding is in line with study conducted by Lawson and Samson (2001). According to Lawson and Samson (2001), innovation strategy serves as the detail action plan and implementation guideline for innovation activities. Hence, innovation strategy is the most important factor for innovation management particularly for organization that newly engaged into innovation world or an innovation based organization operates in a dynamic environment.

Innovation resource management which consists of financial resources, social capital and human resources is regarded by respondents as the second very important factor for innovation management. The finding echoes research conducted by Cooper and Kleinschmidt (2007) which suggested that financial resource is the key factor for innovation success, without sufficient financial support, innovation process will encounter unforeseen problems, unable to proceed smoothly or even failed to start (Cooper \& Kleinschmidt, 2007). In the case of Research University, the commencement of any research project will only takes place post approval of financial resource (i.e. research grant approval). Prior to the approval of research funding, research projects are deposited at feasibility review stage without adding value to the overall innovation performance.

The finding in term of social capital is in line with study done by Zeng et al. (2010). Zeng et al. (2010) suggested that enhancing relationship with external parties (such as industries or other research organizations) widen the opportunity of exploring new innovative ideas, broaden the potential source of financial support, and expedites research and development progress. Hence, social capital is important toward innovation management success. In addition, finding on the important of human resource is in parallel with Panne et al. (2003) who proposed that human resources are important for innovation success because they are the one who can successfully transform new ideas to innovation (Panne et al., 2003). Moreover, Cooper (1983), Roure and Keeley (1990) suggested organization should maintain the balance between technological and human resources capabilities development to ensure success in innovation world.

The other three innovation management success factors, organization culture, organizational structure, and leadership are perceived as factors that important toward innovation management success with the nearly equal means score of 4.11, 4.10 and 4.08 respectively. This suggested that respondents regarded that every factor does play an important role in innovation success. The finding is consistent with prior researchers (Byers et al., 2011; Saleh \& Wang, 1993; Panne et al., 2003; Jacobides, 2007; Balkin \& Logan, 1988; Haas \& Hansen, 2005; Wong, 2005; Cooper \& Kleinschmidt, 2007). According to Byers et al. (2011), a positive organization culture such as trust and cooperation, knowledge sharing, openness to new ideas and tolerance to failure serves as a set of powerful stimulant tools for positive innovative behavior and innovation success in organization. Whereas, in accordance with Saleh and Wang (1993), Panne et al. (2003), and Jacobides (2007), organization structure that allows sufficient flexibility, promote organization's communication and integration, underline task allocation and encourage cross functional teams' cooperation are also important attributes for innovation management success. In addition, leadership which included knowledge of leader, characteristics of leader, subordinates empowerment and reward system are also perceived as important for innovation management which is in line with finding by Balkin and Logan (1988), Haas and Hansen (2005), Wong (2005), Cooper and Kleinschmidt (2007). 


\subsection{Addressing RO2: The Relationship between Innovation Management Success Factors and the Innovation Performance}

Pearson correlation analysis between success factors for innovation management and level of innovation performance in KRA's research groups suggests that innovation resource is strongly and positively correlated with innovation performance. Meantime, weak and positive correlation is observed between leadership and innovation performance, while innovation strategy, organization culture and organization structure are positively and moderately correlated with innovation performance.

Innovation resource is the only factor that strongly and positively correlated with innovation performance. The reason behind the scheme perhaps is because of innovation is complex, costly and long term investment. Moreover, innovation is associated with high level of uncertainty and risk, therefore sufficient resources is needed in order to ensure innovation success (Cooper \& Kleinschmidt, 2007).

As such, suggestion to KRA's research group is to focus on effort on enhancing innovation resources which comprise of financial resource, social capital and human resource management in order to attain greater innovation success. This finding is in line with study conducted by Savignac (2006), Zeng et al. (2010) and Chen and Huang (2009).

Study conducted by Savignac (2006) reveals that focus toward financial support is essential because financial constraint will reduce the availability and likelihood of an organization to undertake research projects, thus implies negative impact toward innovation performance. In term of social capital, research carried out by Zeng et al. (2010) found that there is significant positive relationship between inter-firm, intermediary institution, research organization cooperation with innovation performance. Via good relationship with external parties, an organization could establish a beneficial network that assist the organization to gains a greater access toward resources such as human capital and technology information, which consecutively enhance innovation performance (Kalnins \& Chung, 2006; Packalen, 2007).

In addition, according to study done by Chen and Huang, (2009), effective human resource strategy is positively related with knowledge management capacity which in turn leads to a better innovation performance. A good human resource strategy plays an important role on recruiting and retaining capable employees. Hence, human resource management (HRM) should wisely plan in term of recruitment, training and reward system in order to grow a group of individual that can positively contribute to organization's innovation performance.

Result of Pearson correlation analysis also suggested leadership has a weak positive relationship with innovation performance. The result does partially disagree with previous researches such as Wong (2005), Lee and Chang (2006) which found leadership was crucial and powerful predictors for innovation success. A weak positive relationship between leadership and innovation performance may due to researchers in KRA are grouped as knowledge based workforce. Knowledge based workforce are valuable assets for an organization since they were potential sources of organization's competitive advantages which equipped with skills and knowledge that not transferable to other organization (Rousseau, 1995). However, according to Liu et al. (2003), the group of individual of non-knowledge workforce is more favors on empowering leadership style than an individual of knowledge based workforce. Knowledge based workforce tends to autonomy, emphasize on self-leadership and self-participation in decision making process. As such, due to the behaviors of respondents (who are knowledge based workforce), "leadership" may therefore possess weaker relationship with innovation.

\section{Recommendation and Conclusions}

The study engendered several general implications toward innovation performance and innovation management within KRA research group. The implications could be categorized into two areas, practicability or management implication and theoretical implication.

First, finding from the study revealed that innovation strategy and innovation resources are regarded as the most important factors for innovation success, while the other 3 factors (leadership, organizational structure, and organizational culture) are rated as nearly equal important. However, outcome from Pearson correlation test concluded that innovation resource is the only factor that strongly correlated with innovation performance, and "innovation strategy"; factor that perceived as the most important, is only moderately correlated with innovation performance. (refer Table 9) 
Table 9. Comparison between important ranking and correlation coefficient ranking

\begin{tabular}{ll}
\hline Importance Ranking & Correlation Coefficient Ranking \\
\hline (1) Innovation Strategy & (1) Innovation Resources \\
(2) Innovation Resources & (2) Organizational Culture \\
(3) Organizational Culture & (3) Organizational Structure \\
(4) Organizational Structure & (4) Innovation Strategy \\
(5) Leadership & (5) Leadership \\
\hline
\end{tabular}

Note. (1)-The most important (1)-The highest coefficient (r).

Practically, research efforts must be focused on the right subject. Some researchers often focus on fixing small problems while big problems are ignored, this end up with a poorly focused research (Jongbae \& David, 2009). According to Smith and Rupp (2004), knowledge based worker tends to over focused on strategy planning and inclines to blame strategy as cause of project failure. This perhaps explained why "Innovation Strategy" is rated by respondents as the most important success factor for innovation management in KRA research group.

Over focused on a relatively "less" important success factor for innovation success not only might end up with inefficient innovation process, but might also potentially deprives the research group from new potential research that can be exploited. This possibly is also one of the potential reasons that contribute to the low innovation performance among KRA research group. Hence, finding from this study suggested innovation resources which cover the scope of financial resource, social capital and human resource are the most crucial factor to focus by KRA research group in order to ensure innovation success. Practically, to improve innovation performance, member of KRA are urged to secure a greater research fund, expand collaboration or cooperation with external parties and continuously enhance their level of expertise respectively.

Second, theoretically, there is no single theory of "innovation" that exist (Loch \& Kavadias, 2008); and there is no consensus on whether one theory can and should exist. As such, a revised innovation success framework (refer Figure 2) is formed where innovation success factors are ranked base on the finding of Pearson correlation test (from the highest to the lowest coefficient). The formation of innovation performance framework suggests that a comprehensive innovation management success factor and innovation performance framework exist with the potential to describe a large part of innovation phenomena within KRA research groups.

This study has some limitations that provide worthwhile opportunity for further research. First, although the study covered all projects team within KRA research group, however, the study is limited to a single "research group" sample. Generalizing the research results to university contexts and other research group may not be applicable. Therefore, future research could be done at other faculty or other research groups with the steps and processes modeled from this study; this would contribute to the knowledge of innovation via determination of how the research output differs between faculties or research groups.

Second, the innovation success framework that proposed by the study could be further enhance since the study only focus on the perceived level of important. Hence, future research could expand to assess the level of implementation and implementation effectiveness or via qualitative approach which might provide further insight in this regard. 


\section{Independent Variables}

\begin{tabular}{|l|}
\hline $\begin{array}{l}\text { Innovation Resources } \\
\text { - }\end{array}$ \\
- Sinancial Resource \\
- Human Resource \\
\hline Organization Culture \\
- Openness to Idea and Tolerance \\
to Failure \\
- Trust and Cooperation \\
$\quad$ Knowledge Creation, Learning \\
\end{tabular}

Dependent Variables

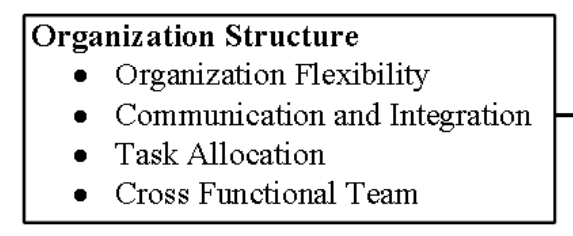

\begin{tabular}{|l|}
\hline Innovation Strategy \\
- Strategy Integration \\
- Strategy Communication \\
- Top Management Commitment
\end{tabular}
Innovation Performance

- Efficiency and Effectiveness of Innovation Process.

- Number of New Project, Services or Product Completed/Developed.

- Research Fund Granted.

- Number of External Links

- Time to Complete a Project

\section{Leadership \\ - Knowledge of Leader \\ - Characteristic of Leader \\ - Leadership Style \\ - Motivation by Leader}

Figure 2. Innovation Management Success Framework for Research University

\section{Acknowledgments}

Authors wish to acknowledge the Malaysian Ministry of Higher Education and Universiti Teknologi Malaysia under the Research Grant (Vote No. 4F323) for sponsoring this publication.

\section{References}

Antonio, H., \& Jose, A. (2008). Innovation Management Techniques and Tools: A Review from Theory and Practice. Journal of R\&D Management, 38(2), 113-127.

Balkin, D., \& Logan, J. (1988). Reward policies that support entrepreneurship. Compensation Benefits Rev., 20(1), 18-25.

Birkinshaw, J., \& Gibson, C. (2004). Building ambidexterity into the organization. Sloan Management Review, $1(45), 47-55$.

Byers, T. H., Dorf, R. C., \& Nelson, A. J. (2011). Technology Ventures From Idea to Enterprise. New York: McGraw-Hill.

Chen, C.-J., \& Huang, J.-W. (2009). Strategic human resource practices and innovation performance-The mediating role of knowledge management capacity. Journal of Business Research, 62, 104-114. http://dx.doi.org/10.1016/j.jbusres.2007.11.016 
Chen, J., Yu, X., Li, W., \& Fu, X. (2008). Critical Factors for SMEs Innovation Performance in Innovation Networks. Industrial Engineering and Enginerring Management, 1684-1688. http://dx.doi.org/10.1109/IEEM.2008.4738159

Chiesa, V. (2001). R\&D strategy and organziation: Managing technical change in dynamic contexts. London: Imperial College Press.

Cooper, R. G. (2008). Make your New Product Process Agile \& Adaptable with "Spiral Development". Product Management, October, 1-2.

Cooper, R. G., \& Kleinschmidt, E. J. (2007). Winning Businesses in Product Development: The Crtitical Success Factors. Research Technology Management, 52-66.

Delbecq, A., \& Mills, P. (1985). Managerial practices that enhance innovation. Organizational Dynamics, 14 (Summer), 24-34.

Evans, J. (1996). Straightforward statistics for the behavioral sciences. Pacific Grove, CA: Brooks/Cole Publishing.

Gloet, M., \& Berrell, M. (2003). The dual paradigm nature of knowledge management: Implications for achieving quality outcomes in human resource management. Journal of Knowledge Management, 7(1), 78-89. http://dx.doi.org/10.1108/13673270310463635

Griffin, A., \& Page, A. (1996). PDMA Success Measurement Project: Recommended Measure for Product Development Success and Failure. Journal of Product Innovation Management, 13(6), 478-496. http://dx.doi.org/10.1111/1540-5885.1360478

Gurteen, D. (1998). Knowledge, Creativity and Innovation. Journal of Knowledge Management, 2, 5-13.

Hartmann, A. (2006). The role of organizational culture in motivating innovative behaviour in construction firms. Construction Innovation, 6(3), 159-172.

Henn, M., Weinstein, M., \& Foard, N. (2006). A Short Introduction to Social Research. London: Sage Publications Ltd.

Horvath, R. (2011). Research \& development and growth: A Bayesian model averaging analysis. Economic Modelling, 2669-2673.

Ismail, K., Leow, Y., C. Y. Yong, I. A.-M., Thwala, W., \& Ajagbe, M. (2012). Critical success factors of new product development in technology based firms: A case study. African Journal of Business Management, 6(33), 9442-9451. http://dx.doi.org/10.5897/AJBM11.2622

Jacobides, M. G. (2007). The inherent limits of organizational structure and the unfulfilled role of hierarchy: Lessons from a near-war. Organization Science, 18(3), 455-477. http://dx.doi.org/10.1287/orsc.1070.0278

Jassawalla, A., \& Sashittal, H. (2002). Cultures that Support Product Innovation Processes. Academy of Management Executive, 42-54.

Johnston, R., \& Bate, J. D. (2007). The Power of Strategy Innovation: A New Way of Linking Creativity and Strategic Planning to Discover Great Business Opportunities. New York: Amacom.

Kalnins, A., \& Chung, W. (2006). Socail Capital, Geography and Survival: Gujarti Immigrant Entrepreneurs in US Lodging Industry. Management Science, 52(2), 233-247.

Kothari, C. R. (2008). Research Methodology: Methods and Techniques. India: New Age International.

Krejcie, R. V., \& Morgan, D. W. (1970). Determining Sample Size for Research Activities. Educational and Psychological Measurement, 30, 607-610.

Larson, E., \& Gobeli, D. (1988). Organizing for product development projects. Journal of Product Innovation Management, 5, 180-190. http://dx.doi.org/10.1111/1540-5885.530180

Lawson, B., \& Samson, D. (2001). Developing innovation capability in organisations: A Dynamic Capabilities Approach. International Journal of Innovation Management, 5(3), 377-400. http://dx.doi.org/10.1142/S1363919601000427

Lee, Y., \& Chang, H. (2006). Leadership style and innovation ability: an empirical study of Taiwanese wire and cable companies. Journal of American Academy of Business, 9(2), 218-223.

Leonard, D., \& Swap, W. (1999). When Sparks Fly: Igniting Creativity in Groups. Boston: Harvard Business Press. 
Loch, C. H., \& Kavadias, S. (2008). Managing new product development: An evolutionary framework. Handbook of New Product Development Management (pp. 1-26). Oxford: Elsevier.

Metrick, A., \& Yasuda, A. (2011). Venture Capital \& the Finance of Innovation (2nd ed.). United States: John Wiley \& Sons, Inc.

Michael, L. (2008). Introduction of an Evaluation Tool to Predict the Probability of Success of Companies: The Innovativeness, Capabilities and Potential Model (ICP). Journal of Technology, Management and Innovation, 4(1) 33-47. http://dx.doi.org/10.4067/S0718-27242009000100004

Mol, M., \& Birkinshaw, J. (2009). The sources of management innovation: When firms introduce new management practices. Journal of Business Research, 26(12), 269-280. http://dx.doi.org/10.1016/j.jbusres.2009.01.001

O’Sullivan, D., \& Dooley, L. (2009). Applying Innovation. United States: SAGE Publication, Inc.

Packalen, K. (2007). Complementing Capital: The Role of Status, Demographic Features and Social Capital in Founding Teams' Abilities to Obtain Resources. Entrepreneurship Theory and Practice, 873-891.

Panne, G. V., Beers, C. V., \& Kleinknecht, A. (2003). Success and Failure of Innovation: A Literature Review. $\begin{array}{llll}\text { International Journal of Innovation } & \text { Management, } & 7(3), & 309-338 .\end{array}$ http://dx.doi.org/10.1142/S1363919603000830

Rahimi, G., Damirchi, G. V., \& Seyyedi, M. H. (2011). Surveying of Organizational Culture and Management Behavior Affect in Organizational Innovation (Case Study: Agriculture Organization of Eastern Azerbaijan in Iran). World Applied Sciences Journal, 14(11), 1763-1769.

Rasli A. (2006). Data analysis and beyond: A practical guide for post-graduate social scientists. Skudai, Malaysia: Penerbit UTM.

Roure, J., \& Keeley, R. (1990). Predictors of success in new technology based ventures. Journal of Business Venturing, 5, 221-239.

Saleh, S. D., \& Wang, C. K. (1993). The Management of Innovation: Strategy, Structure, and Organizational Climate. IEEE Transactions on Engineering Management, 40(1), 14-21. http://dx.doi.org/10.1109/17.206645

Sathe, V. (1989). Fostering entrepreneurship in the large, diversified firm. Organizational Dynamics, 20-32.

Savignac, F. (2006). The impact of financial constraints on innovation: Evidence from french manufacturing firms, Cahiers de la Maison des Sciences Economiques v06042, Université Panthéon-Sorbonne (Paris 1).

Sekaran, U. (2003). Research Method for Business: A Skill Building Approach (4th ed.). New York: John Willey $\&$ Sons.

Smith, A., \& Rupp, W. (2004). Knowledge workers perceptions of performance rating. Journal of Workplace Learning, 16(3), 146-166. http://dx.doi.org/10.1108/13665620410528506

Trott, P. (2005). Innovation Management and New Product Development (3rd ed.). England: Prentice Hall.

Valencia, J. C., Valle, R. S., \& Jimenez, D. (2010). Organizational culture as determinant of product innnovation. European Journal of Innovation Management, 13(4), 466-480.

Weiers, R. M. (2008). Introduction to Business Statistics (6th ed.). United States: Thomson South-Western.

Wong, K. Y. (2005). Critical success factors for implementing knowledge management in small and mediumm enterprises. Industrial Management \& Data System, 105(3), 261-279.

Yulk, G. (2010). Leadership in Organization. New Jersey: Prentice Hall .

Zeng, S., Xie, X., \& Tam, C. (2010). Relationship between cooperation networks and innovation performance of SMEs. Technovation, 30(3), 181-194.

Zikmund, W. (1972). Ethical standards of psychologists. Washington, DC: American Psychological Association.

Zikmund, W. (1997). Business Research Methods (5th ed.). Chicago.: The Dryden Press, Harcourt Brace College Publishers.American Psychological Association. 


\section{Copyrights}

Copyright for this article is retained by the author(s), with first publication rights granted to the journal.

This is an open-access article distributed under the terms and conditions of the Creative Commons Attribution license (http://creativecommons.org/licenses/by/3.0/). 